\title{
CRITICAL DEPTH OF NORMAL CRACKS IN REINFORCED CONCRETE BEAMS OF RECTANGULAR CROSS-SECTION
}

\author{
Vidmantas JOKŪBAITIS, Linas JUKNEVIČIUS \\ Department of Reinforced Concrete and Masonry Structures, Faculty of Civil Engineering, \\ Vilnius Gediminas Technical University, Sauletekio al. 11, LT-10223 Vilnius, Lithuania
}

Received 27 Mar. 2013; accepted 13 May 2013

\begin{abstract}
The evaluation of stress state of longitudinal tensile reinforcement is highly important while examining the technical state of under-reinforced concrete structures. The appearance of yield stress in tensile reinforcement could be treated as the start of incipient failure of the flexural structure. The state of tensile reinforcement of flexural reinforced concrete structures could be examined by observing the properties of normal cracks. This paper presents the analysis of the relationship between various parameters of a normal crack during its development. Some elements of fracture mechanics are used for analysis of stress state in flexural reinforced concrete members. The analytical data are compared to the experimental results, and the adjustment functions are proposed for flexural beams of certain cross section shape, dimensions and reinforcing ratio.
\end{abstract}

Keywords: reinforced concrete; cracks; stress; strain; flexural beams; reinforcement.

Reference to this paper should be made as follows: Jokūbaitis, V.; Juknevičius, L. 2013. Critical depth of normal cracks in reinforced concrete beams of rectangular cross section, Journal of Civil Engineering and Management 19(4): 583-590. http://dx.doi.org/10.3846/13923730.2013.812575

\section{Introduction}

The assessment of stress state in longitudinal tensile reinforcement is highly important while examining the technical state of under-reinforced concrete structures. The most important issue is to determine whether external loads cause the close to yield stress in the main reinforcement. The appearance of yield stress in tensile reinforcement could be treated as the start of incipient failure of the flexural structure (Alam et al. 2010; Gilbert 2008; Jokūbaitis et al. 1993; Kovacs 2010).

The propagation of cracks in flexural reinforced concrete beams is investigated extensively, but such research is usually limited to the serviceability stage, i.e. before the failure starts (Niemen 1967; Sagar 2011; Sharaf, Soudki 2002). Although it is also important to know the characteristics of the critical macro-crack, which causes the actual failure of the member, e.g. the critical depth of a normal crack, and which causes the yield stress in tensile reinforcement, the availability of such research data in scientific literature is limited (Murthy et al. 2009).

The state of tensile reinforcement of flexural reinforced concrete structures could be examined by observing the properties of normal cracks which are the result of stress state in the cross section. Normal cracks could be described by two main properties width at the tensile reinforcement level and depth (height). The development of cracks is uneven at the beginning of the cracking of a flexural beam. The depths of cracks increase suddenly and chaotically. On the other hand, the width of cracks at the level of the main reinforcement increases less noticeably (Carmona et al. 2007; Hamad et al. 2010; Jansson et al. 2012; Jokūbaitis, Kamaitis 2000; Kovacs 2010). Although when yield stress is reached in reinforcement, cracks develop in a different manner. At this stage, the width of cracks rapidly increases, but their depth remains almost stable. The development of cracks and all their parameters is much more stable in prestressed reinforced concrete beams. Such behaviour of cracks was investigated and confirmed by many scientists worldwide (Bažant 2002; Carino, Clifton 1995; Ooi, Yang 2011; Perera, Mutsuyoshi 2013; Rashid, Mansur 2005; Sharaf, Soudki 2002).

The relationship between the depth of a normal crack and the stress state within the cross section of the beam was proven by theoretical and experimental research many years ago. There is a possibility to determine the stress in the main reinforcement by using the data from experimental research. The stress 
in tensile reinforcement could be calculated according to the measured depth of normal cracks in the examined beams under loading (Gerdžiūnas, Rozenbliumas 1973; Jokūbaitis 1967; Niemen 1967; Rozenbliumas 1966; Židonis 1973).

In this paper, according to the fracture mechanics of solids, the refined method for determining the actual state of stress in the main tensile reinforcement by knowing the measured depth of normal cracks and acting bending moment is proposed. Namely, the main purpose is to find out whether the reinforcement has reached its yield stress and, thus, observed normal cracks may be treated as critical and indicating the beginning of incipient failure of the flexural member.

\section{Relationship between the critical depth of the crack and yield stress in the reinforcement}

The calculation model for the crack development (Fig. 1) is based on rules provided by the fracture mechanics of solids (Baluch et al. 1992; Jokūbaitis, Kamaitis 2000; Jokūbaitis, Pukelis 2005; Jokūbaitis et al. 1993; Rabczuk, Belytschko 2006). The two tips of each crack could be determined. One of them causes the propagation of the crack towards the neutral axis of the flexural member. The position of the other tip coincides with the level of tensile reinforcement. The width of the crack tip, which is close to the neutral axis, is critical and generally governs the further crack development.

The cohesion forces in concrete and tensile forces in reinforcing steel (which are equal to concrete tensile strength $f_{c t}$ and stress in the reinforcement $\sigma_{s}$ respectively) resist to the crack development.

The parts of the member separated by the crack rotate around the point, which is an intersection between the crack plane and neutral axis. The distance between the crack surfaces within $h_{c r}$ is proportional to the distance to neutral axis (Fig. 1). The following formula could be written for calculation of stress in tensile reinforcement based on the model shown in Figure 1:

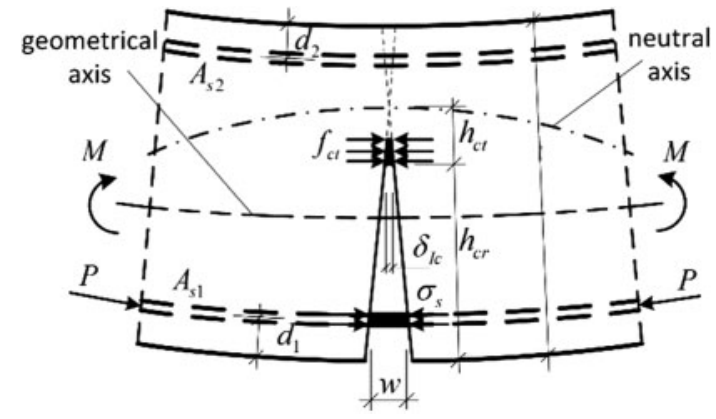

Fig. 1. The model for calculation of normal crack development

$$
\sigma_{s}=0.785\left[\frac{M_{t o t}\left(075 h_{c r}+h_{c t}\right)}{l_{1}}-\frac{P}{A_{1}}\right]\left(\frac{h_{c r}}{t}\right)^{\frac{1}{2}} \alpha \leq \sigma_{y},
$$

where $M_{\text {tot }}=M-P e_{0 p}-\Delta M ; M-$ the bending moment; $P$ - the prestress force; $e_{0 p}-$ the eccentricity of the prestress force; $\Delta M=P\left(y-h_{c r}-h_{c t}\right)$ - the increase of the bending moment caused by matching the geometrical centre and neutral axis in the design cross section; $y$ - the distance from most tensile fibre of cross section to geometrical axis (centre of gravity); $h_{c r}$ - the depth of the crack; $h_{c t}$ - the height of the tensile zone above the crack; $A_{1}$ and $I_{1}$ - the area of the cross section and the second moment of the area, respectively; $b$ - the width of the cross section; $A_{s 1}$ and $A_{s 2}$ - areas of tensile and compressive reinforcement, respectively; $\alpha-$ the dimensionless adjustment function, which depends on the depth of the crack and geometry of the cross section (usually the ratio $\frac{h_{c r}}{h}$ $t=\frac{A_{s 1}}{b} ; \sigma_{y}-$ the yield stress in the tensile reinforcement.

When the yield stress $\sigma_{y}$ is reached in the tensile reinforcement, the tensile zone of concrete above the crack is insignificant and may be neglected, i.e. $h_{c t}=0$. Also, because of significant plastic deformations in the tensile reinforcement, the prestress force $P \approx 0$. Hence, Eqn (1) could be written in the following form:

$$
\sigma_{y} \cong\left(\frac{0.59 M_{u 1} h_{c r, l i m}}{I_{1}^{*}}\right)\left(\frac{h_{c r, l i m}}{t}\right)^{\frac{1}{2}} \alpha,
$$

where $M_{u 1}$ and $h_{c r, l i m}$ - the bending moment and the critical depth of the crack, respectively, when stress in the tensile reinforcement reaches its yield limit $\sigma_{y}\left(\sigma_{0.2}\right.$ or $\left.\sigma_{0.1}\right)$.

The second moment of the area of equivalent design cross section could be calculated according to the following equation:

$$
\begin{aligned}
I_{1}^{*}= & \frac{b h_{1}^{3}}{12}+ \\
& b h_{1}\left(0.5 h_{1}-h_{c r}\right)^{2}+0.5 \alpha_{e} A_{s 1} h_{c r}^{2}+ \\
& \alpha_{e} A_{s 2}\left(h_{1}-h_{c r}-d_{2}\right)^{2}
\end{aligned}
$$

where the height of the equivalent design cross section $h_{1}=-k_{1}+\left(k_{1}^{2}+k_{2}\right)^{\frac{1}{2}} ; k_{1}=\frac{\left(\alpha_{e} A_{s 2}-h_{c r} b\right)}{b} ;\left(\right.$ when $A_{s 2}=$ $\left.0, \quad k_{1}=-h_{c r}\right) ; \quad k_{2}=\frac{2 \alpha_{e}\left(A_{s 2} d_{2}+A_{s 2} h_{c r}+0.5 A_{s 1 h_{c r}}\right)}{b}$ (when $A_{s 2}=0, k_{2}=\frac{\alpha_{e} A_{s 1} h_{c r}}{b}$ ); the depth of the crack $h_{c r}=h_{c r, \text { lim }} ; \alpha_{e}$ - the ratio between the modulus of elasticity of reinforcement and concrete (short term); $d_{2}$ - the distance from most compressive fibre of the cross section to the centre of gravity of the compressive reinforcement.

The precision of Eqn (2) directly depends on the adjustment function $\alpha$, which, in turn, depends on the ratio $\frac{h_{c, \text { chin }}}{h}$, reinforcement ratio $\rho$ and other parameters of a normal crack. 


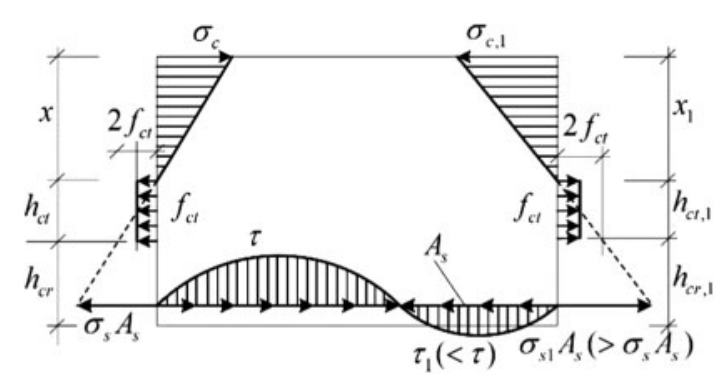

Fig. 2. Damaged equilibrium of bond forces in the zone between two adjacent cracks

\section{Determination of the relationship between the adjustment function $\alpha$ and parameters of a normal crack}

The theory of the relationship between the depth of normal cracks and the stress state in the cross section is based on numerous experimental research data (Jokūbaitis, Pukelis 2005; Rozenbliumas 1966). This theory allows considering the case when the slip between the tensile reinforcement and concrete occurs after a crack appearance, i.e. the hypothesis of plane sections is not valid. In such a case, the deformations in concrete and reinforcement are not equal anymore because of the damaged bond between them (Fig. 2).

According to the theory mentioned earlier, the stress in the tensile reinforcement could be calculated using the following equation system:

$$
\left.\begin{array}{c}
h_{c t}=\frac{\left[\left(I-S h_{c r}\right)-\left(S-A h_{c r}\right) d_{1}-\frac{b h_{c t}^{3}}{12}\right]}{\left[\frac{M}{2 f_{c t}}+S-\left(\frac{P}{2 f_{c t}}+A\right) d_{1}\right]} \\
\sigma_{s}=\frac{2 f_{c t}\left[\frac{\left(S-A h_{c r}\right)}{h_{c r}}-\frac{P}{2 f_{c t}}-A\right]}{A_{s 1}}
\end{array}\right\},
$$

where $A, S, I$ and $M$ - the area of cross section, the first moment of the area, the second moment of the area and the bending moment in respect to the edge of the cross section subjected to the greatest tension, respectively. The area of the cross section within the depth of the crack (including the area of the tensile reinforcement $A_{s 1}$ ) is neglected.

The values of the stress in the tensile reinforcement calculated according to Eqn (4) were similar to the ones obtained from the experimental research on flexural beams of rectangular and tee cross sections (Niemen 1967; Židonis 1973) when beams were loaded by $40-80 \%$ of the ultimate load. The influence of tensile concrete above the crack on the change of stress in reinforcement is insignificant (Gerdžiūnas, Rozenbliumas 1973).

When calculating the stress in reinforcement according to Eqn (4) - in contrast to the method presented in Section 1 - the use of expression $\alpha$ is avoided and thus these equations are suitable for determination of the adjustment factor $\alpha$ itself. The stress in tensile reinforcement $\sigma_{s}$ could be calculated using Eqn (4) and the relationship between $h_{c r}$ and $M$ obtained from experimental research. Then the adjustment function $\alpha$ could be calculated by putting $M_{u 1}$, $h_{c r, \text { lim }}$ and $\sigma_{y}$ values (determined according to Eqn (4)) to Eqn (2) and assuming that $h_{c t}=0$. During the next stage, the influence of ratio $h_{c r \text {, lim }} / h$ and other parameters on the adjustment function $\alpha$ could be determined.

When stress in the tensile reinforcement is close to the yield state ( $\sigma_{s} \approx \sigma_{y}$ ), the strength of compressive concrete remains partially unused (particularly in under-reinforced beams). Thus, in such stress state, the triangular design diagram of stress distribution within the compressive zone is most relevant. When performance of tensile concrete above the crack is neglected - the resistance moment (carrying capacity) of the beam - increases. On the other hand, such increase in the carrying capacity should be reduced because of ignorance of the compressive reinforcement and plastic deformations in compressive concrete.

When taking into account these assumptions (Fig. 3) and the condition of the static equilibrium between the moments of internal and external forces, we can write the following expression for calculation of carrying capacity of the beam:

$$
M_{u 1} \cong \frac{\sigma_{y} A_{s 1}\left(h_{c r, l i m}+2 h-3 d_{1}\right)}{3} .
$$

Equations (2), (4) and (5) results in the same values because of insignificant influence of tensile concrete above the crack on the stress state when calculating the stress $\sigma_{y}$.

The data of experimental research on 28 beams of rectangular cross section were used to analyse the adjustment function $\alpha$. In 26 of these experimental beams, the various prestress degree and low reinforcing ratio were present. The reinforcing ratio in the remaining 2 beams was significantly higher (Girnys 2005; Kupetauskas 2005). The main parameters of experimental beams are given in Table 1 .

All tested beams failed in the pure bending zone, which was in the middle one-third of the beam span. The span for all beams was $1.80 \mathrm{~m}$ with the exception of two S group beams, the span of which was $1.20 \mathrm{~m}$. A relatively small span of some tested beams does not have a significant influence on the crack parameters

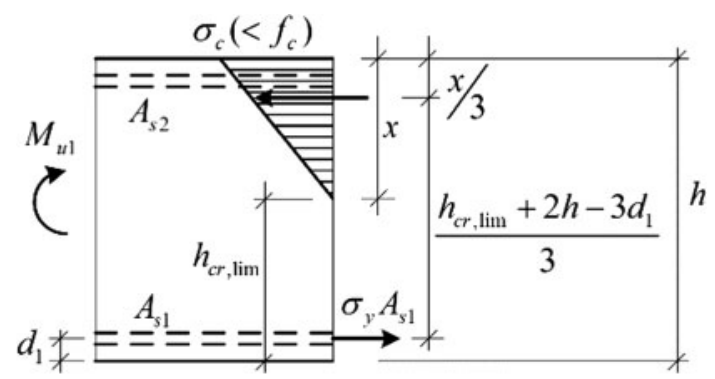

Fig. 3. Design state of stress within the cross section when tensile reinforcement yields 
Table 1. Main parameters of experimental beams

\begin{tabular}{|c|c|c|c|c|c|c|c|}
\hline \multirow[b]{2}{*}{$\begin{array}{l}\text { Test beam } \\
\text { group }\end{array}$} & \multirow[b]{2}{*}{ Quantity } & \multirow[b]{2}{*}{$\begin{array}{l}\text { Dimensions of cross } \\
\text { section } b \times h(\mathrm{~mm})\end{array}$} & \multirow[b]{2}{*}{$\begin{array}{l}\text { Concrete strength } \\
f_{c, \text { cube }}(\mathrm{MPa})\end{array}$} & \multicolumn{4}{|c|}{ Characteristics of tensile reinforcement } \\
\hline & & & & $\begin{array}{c}\rho \\
(\%)\end{array}$ & $\begin{array}{c}P \\
(\mathrm{kN})\end{array}$ & $\begin{array}{l}\text { Quantity of rebars and } \\
\text { their diameter }(\mathrm{mm})\end{array}$ & $\begin{array}{c}\sigma_{y} \\
(\mathrm{MPa})\end{array}$ \\
\hline A & 4 & $100 \times 180$ & 53.4 & 0.79 & 1325 & $6 \emptyset 5$ (hard wire) & 1160 \\
\hline $\mathrm{B}$ & 4 & & 50.0 & & 776 & & \\
\hline $\mathrm{C}$ & 2 & & 54.0 & & 0 & & \\
\hline $\mathrm{D}$ & 4 & & 48.5 & 0.37 & 677 & $3 \emptyset 5$ (hard wire) & \\
\hline A1 & 4 & & 40.5 & 0.94 & 750 & $3 \emptyset 8$ (deformed rebars) & 587 \\
\hline B1 & 4 & & 52.0 & & 473 & & \\
\hline $\mathrm{C} 1$ & 4 & & 55.0 & & 0 & & \\
\hline $\mathrm{S} 1$ & 1 & $100 \times 195$ & 37.2 & 1.82 & 0 & $4 \emptyset 10$ (deformed rebars) & 477 \\
\hline $\mathrm{S} 2$ & 1 & & & & 0 & $4 \emptyset 10$ (even rebars) & 291 \\
\hline
\end{tabular}

within the pure bending moment zone. One beam in each series (including beams S1 and S2) was loaded in steps $0.1 M_{u 2}$ all the way to the incipient failure. The remaining test beams were loaded in steps $0.1 M_{u 2}$ up to the (1.3-1.5) $M_{c r}$ (here $M_{u 2}$ and $M_{c r}$ - ultimate and cracking moments of the beams, respectively) and then unloaded. Then, the beams were loaded up to the $(1.75-2.1) M_{c r}$ and unloaded again. Finally, the beams were loaded in steps $0.2 M_{u 2}$ until the incipient failure. The depths of cracks within the pure bending zone were measured by 24 times magnifying microscope. Depth of one normal crack at the concrete failure point in the compressive zone was additionally monitored by measuring longitudinal deformations. The duration of each loading step was 20 to 30 minutes, thus creep strains were estimated indirectly by measuring crack parameters.

The values of adjustment function $\alpha$ were determined by using the technique described earlier, and the graphs represent the relationship between the depths of normal cracks and bending moments. Also, the clear influence of the ratio $\frac{h_{c r, l i m}}{h}$ and the reinforcing ratio (Fig. 4) on the adjustment function $\alpha$ (when $\sigma_{s}=\sigma_{y}$ ) were determined.

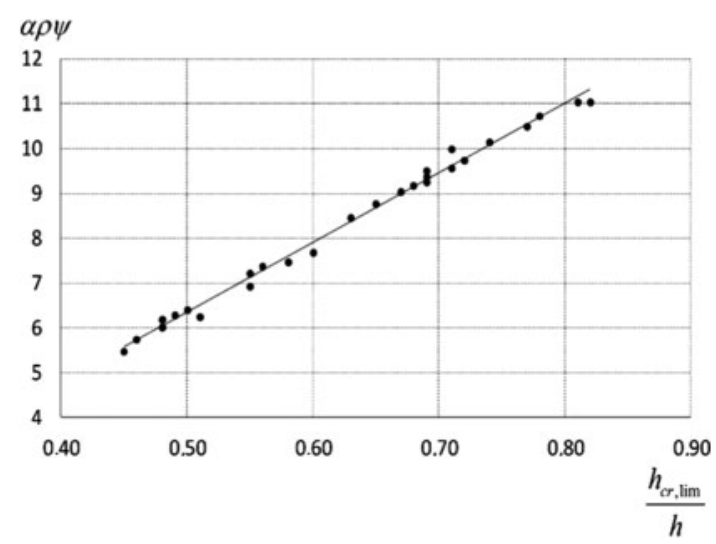

Fig. 4. Relationship between adjustment function $\alpha$ and geometrical characteristics of beams (the correlation coefficient 0.9933)
Adjustment function $\alpha$ could be calculated by the following equation:

$$
\alpha=\frac{\frac{15.53 h_{c r, \text { lim }}}{h}-1.41}{\rho \psi},
$$

where $\rho=\frac{A_{s 1}}{(b d)} 100$ - the reinforcing ratio; $d$ - the design depth of cross section; factor $\psi=1.6$ when $\rho=$ $0.37 \%, \psi=1$ when $\rho=(0.79-1.0) \%$ and $\psi=0.65$ when $\rho=1.82 \%$. The intermediate values of product $\rho \psi$ could be obtained by interpolating. The amount of available experimental data is not enough for presenting the coefficient $\psi$ as a functional factor.

Two stages could be distinguished when analysing normal crack development (Fig. 5).

In the beginning of the first stage, the crack depth $h_{c r}$ increases more rapidly if compared to the crack width (Fig. 5(1)). At the end of the same stage, the crack propagation (the increase in depth) slows down, but the crack width increases faster. During this stage (with the exception of the initial phase), the development of the crack in concrete is stable and the known condition of fracture mechanics $-\delta_{I}=\delta_{I c}-$ could be used as crack development criteria. Here $\delta_{I}$ and $\delta_{I c}$ are the opening width and critical width of the crack tip, respectively $\left(\delta_{I c}=\right.$ const $)$. The stress in the tensile reinforcement $\sigma_{s}$ is smaller than the yield stress $\sigma_{y}$, i.e. the structure at this stage is safe to use.

The second stage of development of a normal crack starts when the yield stress is reached in tensile reinforcement but the compressive stress in concrete is still below the strength limit. During this stage, the rapid opening (widening) of the crack at the level of tensile reinforcement could be observed while the depth of the crack remains almost stable (Fig. 5(2a)). When stress $\sigma_{s}=\sigma_{y}$, shear deformations in compressive concrete resist to the crack propagation towards the neutral axis. It results in the conditions for the formation of longitudinal shear cracks above the tip of a normal crack, i.e. the direction and speed of normal crack propagation changes (Fig. 5(2b)). Thus, different crack development conditions have to be taken 


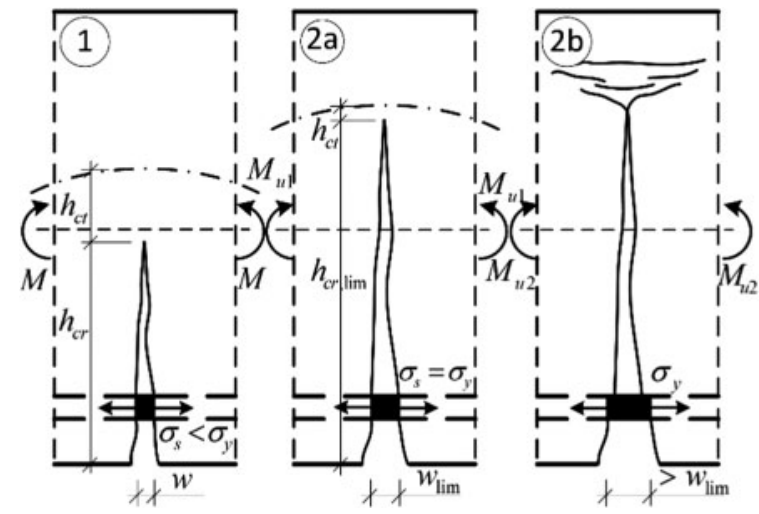

Fig. 5. Stages of development of a normal crack

into account from the point of view of fracture mechanics. The incipient failure of the beam starts at this stage. The beam-resist bending moment $M_{u 1}$ at the beginning of this stage (Eqns (2) and (5)). At the end of the stage (beam failure) when $M=M_{u 2}$, the formation of crack branches at the tip of the crack could be observed (Fig. 5(2b)). Longitudinal cracks in compressive concrete are visible to the naked eye.

The relationship (Fig. 6) between the measured depth of the crack $h_{c r, \text { lim }}$ and depth $h_{c t}$ obtained from Eqn (4) when $\sigma_{s}=\sigma_{y}$, was determined by analysing experimental research data (Table 1).

The height of the tensile concrete zone above the crack:

$$
w=\frac{\delta_{I c} h_{c r}}{h_{c t}} .
$$

The critical width of a normal crack tip during the first stage of crack development:

$$
\delta_{I c}=\frac{0.00012 d_{1} \sqrt[3]{\emptyset \eta}}{\omega}
$$

where $\varnothing$ is the diameter of a reinforcing bar.

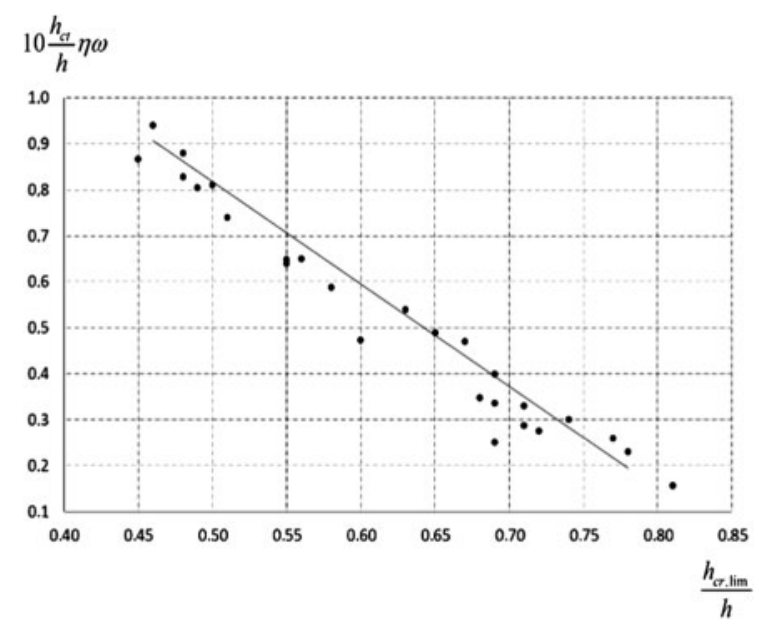

Fig. 6. Relationship between $h_{c r, \text { lim }}$ and $h_{c t}$ (the correlation coefficient 0.9616 )
According to Eqns (7) and (8), the following expression could be written for the second stage of crack development:

$$
w_{\lim }=\frac{h_{c r, l i m} \eta \omega \delta}{0.18 h-0.21 h_{c r, l i m}},
$$

where $\delta$ is the relative width of a normal crack tip.

During the second stage of crack development, $\delta$ should be greater than the critical opening $\delta_{I c}$ because of a significant reduction of intensity of crack propagation towards the neutral axis.

\section{Experimental assessment of critical crack characteristics}

The additional data from experimental research on six beams were analysed in order to verify the assumptions and empirical expressions given in Sections 1 and 2. Beams were tested recently at Vilnius Gediminas Technical University by MSc students J. Šlaitas, P. Verikas and S. Župikovas. All test beams were of rectangular cross section $(b \times h=100 \times 200 \mathrm{~mm})$. Main reinforcing characteristics of the tested specimens are given in Table 2.

The length of the pure bending zone in all tested beams was equal to $0.7 \mathrm{~m}$. Average deformations of the tensile reinforcement were measured by displacement gauges of $200 \mathrm{~mm}$ base. The length increase at the crack was measured by displacement gauge of $50 \mathrm{~mm}$ base. Displacement gauges were fastened to the concrete surface. Deformations of the compressive concrete in mid span were measured by the sequential row of tensors (Fig. 7). The width and depth of cracks were measured by 24 times magnifying microscope. During the initial stage of crack development, loading steps were equal to approximately $0.15 M_{u 2}$. The loading steps were decreased to approximately $0.75 M_{u 2}$ by approaching the yield stress in tensile reinforcement. The duration of each loading step was 10-15 minutes. The deformative and strength characteristics of materials were determined by testing the specimens of standard shape and size. It was determined that the cylindrical compressive strength of concrete is equal to $31.6 \mathrm{MPa}$ and the modulus of elasticity $-40.7 \mathrm{GPa}$.

Table 2. Main reinforcing characteristics of tested beams

\begin{tabular}{lcccccc}
\hline $\begin{array}{l}\text { Test } \\
\text { beam }\end{array}$ & $A_{s}\left(\mathrm{~m}^{2}\right)$ & $\begin{array}{c}\rho \\
(\%)\end{array}$ & $\begin{array}{c}d_{1} \\
(\mathrm{~mm})\end{array}$ & $\begin{array}{c}\varnothing \\
(\mathrm{mm})\end{array}$ & $\begin{array}{c}\sigma_{y} \\
(\mathrm{MPa})\end{array}$ & $\begin{array}{c}E_{s} \\
(\mathrm{GPa})\end{array}$ \\
\hline $\mathrm{B} 1-1$ & 0.000226 & 1.3 & 26 & 12 & 613 & 185.6 \\
$\mathrm{~B} 1-2$ & & & 25 & & & \\
$\mathrm{~B} 1-3$ & & & 26 & & & \\
$\mathrm{~B} 2-1$ & 0.000101 & 0.58 & 24 & 8 & 583 & 193.8 \\
$\mathrm{~B} 2-2$ & & & 24 & & & \\
$\mathrm{~B} 2-3$ & & & 25 & & & \\
\hline
\end{tabular}




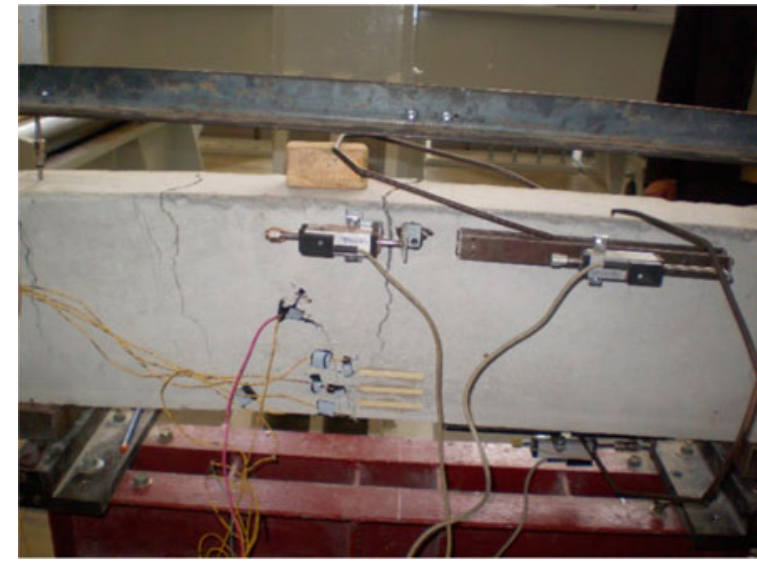

Fig. 7. General view of the test layout (the arrangement of measuring instruments)

The deformations measured with a $50 \mathrm{~mm}$ base displacement gauge at the level of tensile reinforcement could be treated as actual deformations in the reinforcement at cracked section because the decrease of such deformations caused by restraining tensile concrete (when hypothesis of plane sections is valid) is insignificant.

Thus, measured lengthening within $50-\mathrm{mm}$ gauge is approximately equal to the width of the crack at the level of tensile reinforcement and, therefore, the bending moments $M_{u 1, o b s}$, which cause yield stress in the tensile reinforcement, could be easily calculated by using the graphs representing the relationship between such deformations and bending moments, and the change of deformations increases (Table 3). Nevertheless, values of $M_{u 1, o b s}$ were additionally controlled by observing the increase of the crack width and yield deformations of the tested tensile reinforcement bars. The average ratio between bending moments $M_{u 1, o b s} / M_{u 2, o b s}$ was equal to 0.937 and 0.883 for the series B1 and series B2 test beams, respectively. The known rule stating that the difference between $M_{u 1, d}$ (2) and $M_{u 1, d}(5)$ should decrease when increasing the reinforcing ratio was verified.

The bending moment $M_{u 1, d}$ (2) was calculated according to Eqn (2) by using the iteration method when varying adequate values of $M$ and $h_{c r}$ and assuming that stress in tensile reinforcement $\sigma_{s}$ is equal to the yield stress $\sigma_{y}$. Values of $h_{c r, \text { lim }}$ obtained from Eqn (2) were also used for calculation of the bending moment $M_{u 1, d}(5)$, according to the equilibrium condition given in Eqn (5).

On average, bending moments $M_{u 1, d}$ (2) are greater by $4 \%$ than $M_{u 1, d}(5)$ because the performance of tensile concrete above the crack tip is indirectly evaluated by the adjustment function in Eqn (2). On an average, the design values of $M_{u 1, d}(2)$ are lower by $11 \%$ than experimental ones. Such difference is more noticeable in beams with a smaller reinforcing ratio. The adjustment function (6) should be refined for under-reinforced $(\rho \leq 0.8 \%)$ concrete beams (not prestressed).

The value $\delta$ was calculated according to Eqn (10) by using critical characteristics of the crack $w_{\text {lim }}$ and $h_{c r, l i m}$ corresponding to the value $M_{u 1, o b s}$. Then value $\delta$ was compared to the constant $\delta_{I c, 1}$ (Table 3). Calculated values $\delta$ are significantly (1.85 times on the average) greater because the character of crack development changes dramatically when yield stress is reached in the tensile reinforcement.

\section{Conclusions}

1. Together with the known section method when writing the equations of static equilibrium between internal and external forces (Eqns (4) and (5)), the possibilities offered by fracture mechanics (Eqns (1) and (2)) could be used for analysis of the stress state in flexural reinforced concrete members.

2. The adjustment function (6) allows the evaluation of geometrical characteristics of a reinforced concrete member. Although because of the lack of experimental data, this function should be refined for the beams with reinforcing ratio lower than $0.8 \%$ or greater than $1.3 \%$. The adjustment function could be refined by either using the method presented in this paper or directly by the experimental research.

Table 3. The comparison between numerical and measured characteristics of tested beams

\begin{tabular}{|c|c|c|c|c|c|c|c|c|c|c|}
\hline \multirow[b]{2}{*}{ Test beams } & \multirow[b]{2}{*}{$\mathbf{M}_{u 1, o b s}(\mathrm{kNm})$} & \multirow[b]{2}{*}{$\mathbf{M}_{u 2, o b s}(\mathrm{kNm})$} & \multirow[b]{2}{*}{$\frac{M_{u 1, o b s}}{M_{u 1, o b s}}$} & \multicolumn{2}{|c|}{$\mathrm{M}_{u 1, d}(\mathrm{kNm})$} & \multirow[b]{2}{*}{$\frac{M_{u 1, d}(2)}{M_{u 1, o b s}}$} & \multirow[b]{2}{*}{$\frac{M_{u l, d, d}(5)}{M_{u 1, o b s}}$} & \multirow[b]{2}{*}{$\frac{h_{c r, \mathrm{lim}}}{h}$} & \multirow[b]{2}{*}{$w_{\text {lim }}(\mathrm{mm})$} & \multirow[b]{2}{*}{$\frac{\delta}{\delta_{I c}}$} \\
\hline & & & & Eqn (2) & Eqn (5) & & & & & \\
\hline B1-1 & 22.8 & 24.9 & 0.92 & 22.2 & 20.5 & 0.97 & 0.90 & 0.605 & 0.23 & 2.82 \\
\hline B1-2 & 23.8 & 25.4 & 0.94 & 22.9 & 31.3 & 0.96 & 0.89 & 0.680 & 0.24 & 1.91 \\
\hline B1-3* & $24.5^{*}$ & 25.7 & 0.95 & 22.6 & 20.8 & 0.92 & 0.85 & 0.640 & 0.20 & 2.00 \\
\hline B2-1 & $11.0^{*}$ & 12.5 & 0.88 & 9.30 & 9.30 & 0.85 & 0.85 & 0.730 & 0.20 & 1.27 \\
\hline B2-2 & 11.3 & 12.7 & 0.89 & 9.26 & 9.28 & 0.82 & 0.82 & 0.725 & 0.22 & 1.46 \\
\hline B2-3 & 11.1 & 12.6 & 0.88 & 9.16 & 9.13 & 0.83 & 0.82 & 0.700 & 0.21 & 1.65 \\
\hline
\end{tabular}

*-bending moment was determined according to the increase of crack width measured by the microscope at the failure plain of the beam ( $50 \mathrm{~mm}$ base displacement gauge measured the deformations in different place of the specimen) 
3. Based on the experimental research data presented in this paper, Eqns (2) and (5) allow the accurate enough calculation of the critical depth of a normal crack and the bending moment of flexural beams of rectangular cross section, when the reinforcing ratio is within the range $0.8-1.3 \%$ and the tensile reinforcement yields.

4. The relation between the characteristics of normal cracks described in Eqn (8) cannot be used when stress in tensile reinforcement of flexural beam equals to yield stress because $\delta>\delta_{I c}$.

\section{References}

Alam, S. Y.; Lenormand, T.; Loukili, A.; Regoin, J. P. 2010. Measuring crack width and spacing in reinforced concrete members, in Proc. of the 7th International conference on Fracture Mechanics of Concrete and Concrete Structures, 23-27 May, 2010, Korea, Seoul, 377-382.

Baluch, M. H.; Azad, A. K.; Ashwavi, W. 1992. Fracture mechanics application to reinforced concrete members in flexure, in Carpinteri, A., (Ed.). Applications of fracture mechanics to reinforced concrete, London: Taylor \& Francis, 413-436.

Bažant, Z. P. 2002. Concrete fracture model: testing and practice, Engineering Fracture Mechanics 69(2): 165205. http://dx.doi.org/10.1016/S0013-7944(01)00084-4

Carino, N. J.; Clifton, J. R. 1995. Prediction of cracking in reinforced concrete structures. Gaithersburg, MD: NISTIR 5634. National Institute of Standards and Technology (NIST). 50 p.

Carmona, J. R.; Gonzalo, R.; del Viso, J. R. 2007. Mixedmode crack propagation through reinforced concrete, Engineering Fracture Mechanics 74(17): 2788-2809. http://dx.doi.org/10.1016/j.engfracmech.2007.01.004

Gerdžiūnas, P.; Rozenbliumas, A. 1973. Deformations in compressive zone of flexural reinforced concrete members with flanges, Reinforced Concrete Structures 5: 43-54 (in Russian).

Gilbert, R. I. 2008. Control of flexural cracking in reinforced concrete, ACI Structural Journal 105(3): 301-307.

Girnys, M. 2005. The analysis of longitudinal reinforcement stresses calculation methods in cracked reinforced concrete beams. MSc thesis. Vilnius: Vilnius Gediminas Technical University. 42 p. (in Lithuanian).

Hamad, W.; Owen, J.; Hussein, M. 2010. Modelling the nonlinear behaviour of a cracked reinforced concrete beam, in Tizani, W., (Ed.). Procedings of the International Conference "Computing in Civil and Building Engineering”, 30 June-2 July, 2010, Nottingham: Nottingham University Press, Paper 227, 453 p.

Jansson, A.; Flansbjer, M.; Loefgren, I.; Lundgren, K.; Gylltoft, K. 2012. Experimental investigation of surface crack initiation, propagation and tension stiffening in self-compacting steel-fibre-reinforced concrete, Materials and Structures 45: 1127-1143.

Jokūbaitis, V. 1967. Influence of consistent and accidental cracks on reinforced concrete beams subjected to short-term loading. PhD thesis. Kaunas. 235 p. (in Lithuanian).
Jokūbaitis, V.; Kamaitis, Z. 2000. Cracking and repair of reinforced concrete structures: Monograph. Vilnius: Technika. 155 p. (in Lithuanian).

Jokūbaitis, V.; Pukelis, P. 2005. Influence of longitudinal reinforcement on development of normal cracks, Journal of Civil Engineering and Management 11(1): 33-37.

Jokūbaitis, V.; Pukelis, P.; Kaminskas, K. A. 1993. Stress assessment of reinforced concrete structures with cracks, in Proc. of IABSE Colloquium, Copenhagen 1993: Remaining Structural Capacity, 1993, Copenhagen, Denmark, 141-147.

Kovacs, T. 2010. Crack-related damage assessment of concrete beams using frequency measurements. PhD thesis. Budapest. 170 p.

Kupetauskas, A. 2005. Connection between parameters of cracks and position of tensile reinforcement in crosssection. MSc Thesis. Vilnius: Vilnius Gediminas Technical University. 65 p. (in Lithuanian).

Murthy, A. R. C.; Palani, G. S.; Iyer, N. R. 2009. State-ofthe-art review on fracture analysis of concrete structural components, Sadhana 34(2): 345-367. http://dx.doi.org/10.1007/s12046-009-0014-0

Niemen, V. N. 1967. Experimental research on deformations of flexural reinforced concrete members subjected to static loading. Doctoral Thesis summary. Kaunas. 25 p. (in Russian).

Ooi, E. T.; Yang, Z. J. 2011. Modelling crack propagation in reinforced concrete using a hybrid finite elementscaled boundary finite element method, Engineering Fracture Mechanics 78(2): 252-273. http://dx.doi.org/10.1016/j.engfracmech.2010.08.002

Perera, S. V. T. J.; Mutsuyoshi, H. 2013. Shear behavior of reinforced high-strength concrete beams, ACI Structural Journal 110(1): 43-52.

Rabczuk, T.; Belytschko, T. 2006. Application of particle methods to static fracture of reinforced concrete structures, International Journal of Fracture 137(1-4): 19-49. http://dx.doi.org/10.1007/s10704-005-3075-z

Rashid, M. A.; Mansur, M. A. 2005. Reinforced highstrength concrete beams in flexure, ACI Structural Journal 102(3): 462-471.

Rozenbliumas, A. 1966. Calculation of reinforced concrete structures by considering the tensile stress in concrete, Research on Reinforced Concrete 1: 3-32 (in Russian).

Sagar, R. V. 2011. Damage assessment reinforced concrete beams using acoustic emission technique, in Proc. of the National Seminar and Exhibition on Non-Destructive Evaluation (NDE 2011), 8-10 December, 2011, Chennai, India, 128-132.

Sharaf, H.; Soudki, K. 2002. Strength assessment of reinforced concrete beams with debonded reinforcement and confinement with CFRP Wraps, in Proceedings of 4th Structural Speciality Conference of the Canadian Society for Civil Engineering, 5-8 June, 2002, Montreal, Quebec, Canada, 10 p.

Židonis, I. 1973. Research on stress and strain in reinforced concrete with various tensile zone and subjected to static short-term loading, Reinforced Concrete Structures 5: 55-65 (in Russian). 
Vidmantas JOKŪBAITIS. Associate Professor, PhD, Department of Reinforced Concrete and Masonry Structures, Faculty of Civil Engineering, Vilnius Gediminas Technical University. Author and coauthor of four text books and more than 100 scientific papers. Research interests: Fracture mechanics and strengthening of reinforced concrete structures, Experimental investigations and Evaluation of building structures.

Linas JUKNEVIČIUS. Associate Professor, PhD, Department of Reinforced Concrete and Masonry Structures, Faculty of Civil Engineering, Vilnius Gediminas Technical University. Author and coauthor of more than 10 scientific papers. Research interests: Layered reinforced concrete structures, Fibre reinforced and lightweight concrete, Experimental and numerical investigations on cracking of flexural reinforced concrete structures. 